\title{
Enhancement, extension, and reversal of the frequency selectivity effect
}

\author{
TODD A. MONDOR and JENNIFER HURLBURT \\ University of Manitoba, Winnipeg, Manitoba, Canada \\ and \\ LISA GAMMELL \\ Dalhousie University, Halifax, Nova Scotia, Canada
}

\begin{abstract}
The influence of a frequency cue on judgments of whether or not a subsequent target incorporated a brief silent gap was examined. In Experiment 1, there was no predictive frequency relation and evidence of auditory inhibition of return was obtained with frequency repetitions, producing a facilitative effect at 175-msec stimulus onset asynchrony (SOA) and an inhibitory effect at 775-msec SOA. Relative to this baseline performance pattern, increasing the probability of a frequency match to .75 (Experiment 2) served to generate a beneficial effect of frequency repetitions at lengthy SOAs and to enlarge its magnitude at 175-msec SOA. In contrast, a reduction in the probability of a frequency match to .25 (Experiment 3) resulted in the elimination of any facilitative effect of repetition at 175-msec SOA and the development of an inhibitory effect at 475- and 1,075-msec SOA. These results establish that a frequency cue may engage both exogenous and endogenous attentional processes within 175 msec following its presentation.
\end{abstract}

Empirical investigation of attention as an important influence on perception began in earnest in the 1950s with germinal studies by Broadbent (e.g., 1952, 1954, 1957, 1958), Cherry (1953; Cherry \& Taylor, 1954), and Moray (1959), among others. Although a variety of experimental paradigms were used in this early research, most studies were directed toward determining the factors that influence accurate perception of speech. Some of these investigations revealed that speech is most likely to be perceived accurately when it differs in location from concurrent white noise (Hirsch, 1950; Kock, 1950), and when speech and noise channels are out of phase with one another (Licklider, 1948). Other studies established that perception of one of two concurrent verbal messages is improved when there are differences between messages in location (e.g., Cherry, 1953; Moray, 1959, 1972), pitch (as defined by a difference in the sex of speaker pronouncing each message, Broadbent, 1952), loudness (Tolhurst \& Peters, 1956), frequency spectrum (created by high-pass or low-pass filtering of one message; e.g., Egan, Carterette, \& Thwing, 1954; Spieth, Curtis, \& Webster, 1954), or phonology (Peters, 1954).

These early years of research into selective listening, then, yielded quite strong evidence that perception of ver-

This research was supported by grants awarded to T.A.M. from the Natural Sciences and Engineering Research Council of Canada. Correspondence should be addressed to T. A. Mondor, Department of Psychology, P429 Duff Roblin Building, University of Manitoba, Winnipeg, MB, R3T 2N2 Canada (e-mail: todd_mondor@umanitoba.ca). bal information may be enhanced if an attended speech channel differs from other irrelevant channels in such fundamental acoustic features as location and pitch. Although research in this area has continued (e.g., Dawson \& Schell, 1982; Giard, Collet, Bouchet, \& Pernier, 1994; Glucksberg \& Cowen, 1970; Katzin, Corballis, \& Lockhart, 1972; Niccum, Speaks, Katsuki-Nakamura, \& Leathers, 1989; Treisman, Squire, \& Green, 1974), scientific emphasis has clearly shifted with the result that research efforts are now largely directed toward developing an understanding of the characteristics and mechanisms of visual selective attention (for reviews see LaBerge, 1995; Pashler, 1998). However, one stream of research within the realm of selective listening that has been continuously active is centered on developing an understanding of the improvement in perception of nonverbal sounds that may result when a particular frequency region is attended (e.g., Creelman, 1959; Green, McKey, \& Licklider, 1959; Macmillan \& Schwartz, 1975; Moore, Hafter, \& Glasberg, 1996; Schlauch \& Hafter, 1991; Swets, 1963). Most studies of this "frequency selectivity effect" have been founded on a simple cuing paradigm. Typically, on each of many trials, a suprathreshold pure tone cue is presented followed by either one or two noise-filled intervals. Although listeners are required to detect the presence of a pure tone target, this may be based on either an assessment of whether the single interval presented included a target (e.g., Larkin \& Greenberg, 1970 ) or on a judgment of which of the two intervals presented included a target (e.g., Greenberg \& Larkin, 1968). The results of such studies have invariably indicated that the probability of an accurate detection response is mod- 
ulated by the frequency relation between the cue and the target, with performance declining as the frequency difference between the two sounds increases (e.g., Green, 1961; Hafter, Schlauch, \& Tang, 1993; Hübner \& Hafter, 1995; Moore et al., 1996; Yama \& Robinson, 1982). This frequency selectivity effect is often quite specific, with very poor performance evident for signals that differ in frequency from the expected sound by just $10 \%$.

Detection accuracy in these experiments has been commonly interpreted as a bias-free measure of sensitivity either because the probability of a target being embedded in the first and second intervals is equal or because a target is embedded in the single noise-filled interval on only half of the trials. There is, however, some reason to doubt this interpretation because in many studies the listener is misled regarding the possible frequencies of the target that may be presented. Whereas participants are led to believe that the pure tone target they are to listen for may be only of a single, specific frequency, targets of a variety of different frequencies are actually presented (e.g., Greenberg \& Larkin, 1968). This deception permits the possibility that, regardless of any effect of the frequency cue itself, participants in these experiments may be more likely to interpret signals of the expected frequency as targets and to interpret signals of unexpected frequencies as noise (Greenberg \& Larkin, 1968, have also advanced this argument). It is possible, then, that in some studies of frequency selectivity a detection response may be influenced by response biases, with listeners giving more weight to cued frequency regions, thereby producing better performance for expected targets (see also Kinchla, 1992). Indeed, evidence has been reported indicating that the specificity of the frequency selectivity effect may be dramatically influenced by the information supplied to the listener. For example, Penner (1972) reported that informing listeners of the possibility that targets of a variety of frequencies could be presented and encouraging them through monetary payoffs to perform as well as possible in detecting all frequencies led to quite good performance for all possible targets (see also Scharf, Quigley, Aoki, Peachey, \& Reeves, 1987, who found that the probability of detecting outlying frequencies could be improved by about $10 \%$ if listeners were informed that such sounds might be presented).

This potential problem may compromise interpretation of performance even when listeners are accurately informed that multiple frequencies are possible if one of these frequencies is more likely to be presented than the others. Under such circumstances, listeners may adopt different criteria for deciding whether a target has been presented in accordance with the individual probabilities of their occurrence (e.g., Shaw, 1980, 1984). In recognition of this possibility, Mondor and Bregman (1994) suggested that frequency selectivity could be studied by presenting listeners on each trial with a clearly audible frequency cue followed by a clearly audible pure tone target. In their study a target duration judgment was used because it is orthogonal to the manipulation of cue-target frequency similarity and therefore should be uninfluenced by any re- sponse biases initiated in reaction to the presentation of the cue. Strong evidence of frequency selectivity was apparent in all three of the experiments reported by Mondor and Bregman, with judgments of duration made consistently more quickly and accurately when the target frequency matched that of the preceding cue than when it did not. Furthermore, they found, as had previous researchers, that performance declined steadily as the frequency difference between the cue and target increased. To the extent that the paradigm used by Mondor and Bregman constrains the influence of response biases on performance, their results suggest that frequency selectivity results because of a modulation in perceptual sensitivity produced by a frequency cue.

Informative frequency cues, such as those that have been used in most previous studies of frequency selectivity, may act both to draw attention to its frequency region through the operation of a stimulus-driven or bottom-up mechanism and to function as a catalyst for a top-down mechanism that deploys attention in accordance with the probability that the cue provides an accurate indication of the likely frequency of the target (see, e.g., McCormick, 1997; Müller \& Rabbitt, 1989; Pashler, 1998; Posner, 1978, who have advanced similar arguments regarding the influence of visual spatial cues on visual selective attention). ${ }^{1}$ Recent studies have shown that a beneficial effect of frequency repetition may emerge within $200 \mathrm{msec}$ following presentation of an uninformative frequency cue (Mondor \& Breau, 1999; Mondor, Breau, \& Milliken, 1998). If, as is widely assumed, uninformative cues exert their influence primarily through automatic engagement of an exogenous attentional process (e.g., Pashler, 1998), then these studies provide evidence that the frequency selectivity effect does not depend entirely on an endogenous attentional mechanism. Uncertainty remains, however, regarding the extent to which endogenous and exogenous processes engaged by a frequency cue may interact in controlling the attentional response to a frequency cue. The three experiments reported below were designed to address this general question through specific examination of the speed with which an endogenous process may be engaged by an informative frequency cue, and the relative influence on performance of endogenous and exogenous processes when these are placed in opposition with each other.

\section{GENERAL METHOD}

All of the experiments reported below are founded on the simplified frequency cuing paradigm used by Mondor and Bregman (1994). Here, however, the influence of a frequency cue is evaluated as a function of both the time between the cue and the target (ranging from less than $200 \mathrm{msec}$ to more than $1 \mathrm{sec}$ ) and the degree to which it provides accurate information regarding the likely frequency of the subsequent target. In this way, we sought to reveal the degree to which frequency selectivity may be modulated by exogenous and endogenous attentional processes.

\section{Participants}

Sixty undergraduate students enrolled in an introductory psychology course received course credit in exchange for their partici- 
pation. Twenty volunteers participated in each of the three experiments. None of the participants reported any uncorrected auditory or visual-perceptual deficiencies.

\section{Materials}

Four pure tones, all $50 \mathrm{msec}$ in duration with 5-msec onset/offset amplitude ramps, were synthesized using the MITSYN signal processing software package (Henke, 1990) at a sampling rate of $32000 \mathrm{~Hz}$. The frequency of two of these sounds was set to $500 \mathrm{~Hz}$ and the frequency of the other two sounds was set to $1711 \mathrm{~Hz}$ (frequencies were arbitrarily chosen with the constraint that they not be harmonically related). One sound of each frequency was interrupted at its midpoint by an abrupt $1-\mathrm{msec}$ silent period. This interruption is perceived as a brief click. The experiment was controlled by a Dell Pentium computer (Model XPS T550) running the Maple programming environment (Bregman, Achim, \& Ahad, 1992). Sounds were presented in stereo at approximately $65 \mathrm{~dB}$ SPL over Sennheiser HD 265 linear headphones.

\section{Procedure}

Each trial consisted of a cue followed by a target. The two sounds could be either identical or different in frequency. In the interests of expository simplicity, trials on which the target repeated the frequency of the cue will be referred to as repeat trials, and trials on which the target differed from the cue will be referred to as change trials. The time period between the onset of the cue and the onset of the target (stimulus onset asynchrony, SOA) was varied at 175, 475, 775 , or $1,075 \mathrm{msec}$ in all experiments. Twenty different listeners participated in each of the three experiments. The experiments differed in the probability that the cue and target would be identical in frequency. Specifically, whereas in Experiment 1 the cue and target were as likely to be the same as to be different (i.e., the cue was uninformative), in Experiment 2 the cue and target were more likely to be the same $(p=.75)$ than to be different $(p=.25)$, and in Experiment 3 the sounds were more likely to be different $(p=.75)$ than to be the same $(p=.25)$.

Participants were required to make a keypress response to indicate whether or not the target incorporated a silent gap ("1" for yes and " 0 " for no). If a correct response was made, a message stating "Press any key to continue." appeared on the screen. In the event of an incorrect response, a message stating "Incorrect Response. Press any key to continue." appeared on the screen. In both cases the subsequent trial began $1 \mathrm{sec}$ following the initiating keypress. Participants were instructed to respond as quickly and accurately as possible since their speed and accuracy would be recorded.

In the statistical analysis of the results of each experiment, response time (RT) was examined only for correct responses, and RTs greater than $2.5 S D$ from the mean were excluded. This resulted in the elimination of less than $2 \%$ of responses in all conditions of all experiments. In all experiments performance as indexed by both mean RT and percent errors was initially evaluated using two-way within-subjects analyses of variance (ANOVAs) (frequency repetition [repeat, change] $\times \operatorname{SOA}[175,475,775,1,075 \mathrm{msec}])$.

\section{EXPERIMENT 1}

Experiment 1 served both to establish a baseline against which to evaluate results obtained in Experiments 2 and 3 and as an opportunity to replicate previous findings that uninformative frequency cues may facilitate target identification even at quite brief SOAs (Mondor \& Breau, 1999; Mondor et al., 1998). This was accomplished by setting the probability of a frequency match between cue and target to chance levels to eliminate any logical reason for listeners to voluntarily use the frequency information provided by the cue to prepare for the target. Listeners completed 32 practice and 224 experimental trials ( 56 trials per SOA with cue and target frequencies identical on 28 trials and different on 28 trials).

\section{Results}

Response times. Mean RTs and percent errors as a function of frequency repetition and SOA are described in Table 1 . The RT analysis revealed that both frequency repetition $[F(1,19)=8.555, p<.01]$ and SOA $[F(3,57)=$ 7.376, $p<.001]$ significantly influenced performance. Generally, RT was faster on repeat trials and declined as SOA increased. In addition, however, an interaction between frequency repetition and SOA was apparent $[F(3,57)=$ $10.665, p<.001]$. The planned comparisons (two-tailed $t$ tests) performed to evaluate this effect indicated that a significant performance advantage for frequency repetitions at both $175-\mathrm{msec}(p<.01)$ and $475-\mathrm{msec}(p<.03)$ SOAs reversed to an advantage for frequency changes at the 775 -msec SOA $[F(1,34)=13.197, p<.01]$. There was no effect of frequency repetition at the $1,075-\mathrm{msec}$ SOA $(p>.30)$.

Errors. A complementary analysis of the error data revealed neither significant main effects of frequency repetition or SOA $[F(1,19)=1.560, p=.23$, and $F<1$, respectively] nor a significant interaction between these factors $(F<1)$. Planned comparisons performed to evaluate the effect of frequency repetition at each SOA revealed no significant effects ( $p$ values of $.90, .11, .40$, and .49 at SOAs of $175,475,775$, and $1,075 \mathrm{msec}$, respectively).

\section{Discussion}

The results of Experiment 1 provided clear evidence of a facilitative effect of uninformative frequency cues at brief SOAs, confirming previous reports that the existence

Table 1

Mean Response Times (RTs) and Percent Errors (\% E), With Standard Errors, as a Function of Frequency Repetition (Repeat or Change) and SOA $(175,475,775$, or $1,075 \mathrm{msec})$ for Experiment 1

\begin{tabular}{|c|c|c|c|c|c|c|c|c|c|c|c|c|c|c|c|c|}
\hline \multirow{4}{*}{$\begin{array}{l}\text { Frequency } \\
\text { Repetition }\end{array}$} & \multicolumn{16}{|c|}{ Stimulus Onset Asynchrony } \\
\hline & \multicolumn{4}{|c|}{$175 \mathrm{msec}$} & \multicolumn{4}{|c|}{$475 \mathrm{msec}$} & \multicolumn{4}{|c|}{$775 \mathrm{msec}$} & \multicolumn{4}{|c|}{$1,075 \mathrm{msec}$} \\
\hline & \multicolumn{2}{|c|}{ RT } & \multicolumn{2}{|c|}{$\% \mathrm{E}$} & \multicolumn{2}{|c|}{ RT } & \multicolumn{2}{|c|}{$\% \mathrm{E}$} & \multicolumn{2}{|c|}{ RT } & \multicolumn{2}{|c|}{$\% \mathrm{E}$} & \multicolumn{2}{|c|}{ RT } & \multicolumn{2}{|c|}{$\% \mathrm{E}$} \\
\hline & $M$ & $S E$ & $M$ & $S E$ & $M$ & $S E$ & $M$ & $S E$ & $M$ & $S E$ & $M$ & $S E$ & $M$ & $S E$ & $M$ & $S E$ \\
\hline Repeat & 581 & 25.04 & 4.29 & 1.26 & 560 & 18.41 & 2.32 & 0.70 & 575 & 21.05 & 2.87 & 0.81 & 554 & 18.31 & 3.39 & 1.14 \\
\hline Change & 626 & 28.34 & 4.11 & 1.04 & 586 & 22.40 & 4.29 & 1.02 & 552 & 18.61 & 4.11 & 1.14 & 561 & 17.85 & 4.46 & 1.39 \\
\hline
\end{tabular}


of a frequency selectivity effect depends on neither misleading listeners regarding probable target frequencies nor on establishing an informative frequency relation between cue and target. Furthermore, the transition in the influence of frequency repetitions from a beneficial effect at the 175- and 475-msec SOAs to a negative effect at the 775msec SOA replicates a pattern of performance previously interpreted as providing evidence of frequency-based inhibition of return (Mondor \& Breau, 1999; Mondor et al., 1998). That these results were obtained when performance was assessed on the basis of a judgment orthogonal to the frequency manipulation confirms that response biases initiated in reaction to the presentation of a cue do not hold an important position in producing them. Quite aside from replicating previous research, the pattern of performance established in this experiment is important in that it will be used as a standard against which to evaluate the influence on the frequency selectivity effect of establishing a predictive relation between the cue and target.

\section{EXPERIMENT 2}

As we have discussed, theoretically important questions relating to the frequency selectivity effect that have not yet been resolved have to do with the nature of the interaction between endogenous and exogenous attentional processes, and the time required for endogenous processes to be engaged in reaction to an informative cue. In Experiment 2, the probability of a frequency match between cue and target was increased to .75 and the influence of frequency repetition on target judgments was examined across the same range of SOAs used in Experiment 1 . At issue, of course, was the extent to which this increase in the accuracy of the information supplied by the frequency cue might change its influence on target identification performance relative to that apparent in Experiment 1 , where there was no predicative relation between the frequencies of the cue and target. Participants completed 32 practice trials and 256 experimental trials (32 trials at each of four SOAs [175, 475, 775, 1,075 msec], with cue and target frequencies identical on 48 trials and different on 16 trials).

\section{Results}

Response times. Mean RTs and percent errors as a function of frequency repetition and SOA are described in Table 2. The results of the ANOVA indicated that both main effects of frequency repetition $[F(1,19)=68.988$, $p<.001]$ and SOA $[F(3,57)=11.235, p<.001]$ were significant. Generally, performance was better when target frequency repeated cue frequency and improved as SOA increased. The frequency repetition $\times$ SOA interaction was also significant $[F(3,57)=14.975, p<.001]$. This interaction arose because of a substantially larger improvement in performance as SOA increased from 175 to $475 \mathrm{msec}$ for change trials $[F(1,19)=23.117, p<.001]$ relative to repeat trials $[F(1,19)=1.384, p=.26]$. Planned comparisons of performance on repeat and change trials at each SOA revealed a consistent advantage for frequency repetitions at all SOAs $(p<.01$ at the 175-, 775-, and 1,075 -msec SOAs, and $p<.025$ at the 475 -msec SOA). The magnitude of the performance advantage for frequency repetitions was significantly larger at the 175msec SOA than at any of the other three SOAs $(p<.01$ for all comparisons).

Errors. A complementary ANOVA of the error data indicated that whereas the main effect of frequency repetition $[F(1,19)=25.703, p<.001]$ reached significance, neither the main effect of SOA $[F(3,57)=1.534, p=.22]$ nor the interaction between frequency repetition and SOA $[F(3,57)=1.383, p=.26]$ was significant. Although error rates were lower for frequency repetitions at all SOAs, planned comparisons revealed that this was significant only at the $775-\mathrm{msec}(p<.01)$ and $1,075-\mathrm{msec}$ $(p<.01)$ SOAs and not at $175-\mathrm{msec}(p>.50)$ or 475 msec SOAs $(p=.09)$.

\section{Discussion}

On the strength of previous investigations of frequency selectivity, we expected that target identification performance would be facilitated when cue and target frequencies matched. The results obtained in this experiment of course confirmed this expectation. Somewhat surprisingly, however, the magnitude of the beneficial effect of frequency repetitions at the briefest SOA of $175 \mathrm{msec}$ was substantially larger than the corresponding effect apparent in Experiment 1. Performance in Experiments 1 and 2 was compared to determine whether the predictability of the cue-target frequency relation significantly influenced performance. ${ }^{2}$ This analysis confirmed that the magnitude of the facilitative effect of a frequency cue was significantly larger in Experiment 2 than in Experiment 1 at three of the four SOAs, including the briefest interval tested of $175 \mathrm{msec}$. There was no difference in the magnitude of the

Table 2

Mean Response Times (RTs) and Percent Errors (\% E), With Standard Errors, as a Function of Frequency Repetition (Repeat or Change) and SOA $(175,475,775$, or 1,075 Msec) for Experiment 2

Stimulus Onset Asynchrony

\begin{tabular}{|c|c|c|c|c|c|c|c|c|c|c|c|c|c|c|c|c|}
\hline \multirow{4}{*}{$\begin{array}{l}\text { Frequency } \\
\text { Repetition }\end{array}$} & \multicolumn{16}{|c|}{ Stimulus Onset Asynchrony } \\
\hline & \multicolumn{4}{|c|}{$175 \mathrm{msec}$} & \multicolumn{4}{|c|}{$475 \mathrm{msec}$} & \multicolumn{4}{|c|}{$775 \mathrm{msec}$} & \multicolumn{4}{|c|}{$1,075 \mathrm{msec}$} \\
\hline & \multicolumn{2}{|c|}{ RT } & \multicolumn{2}{|c|}{$\% \mathrm{E}$} & \multicolumn{2}{|c|}{ RT } & \multicolumn{2}{|c|}{$\% \mathrm{E}$} & \multicolumn{2}{|c|}{ RT } & \multicolumn{2}{|c|}{$\% \mathrm{E}$} & \multicolumn{2}{|c|}{ RT } & \multicolumn{2}{|c|}{$\% \mathrm{E}$} \\
\hline & $M$ & $S E$ & $M$ & $S E$ & $M$ & $S E$ & $M$ & $S E$ & $M$ & $S E$ & $M$ & $S E$ & $M$ & $S E$ & $M$ & $S E$ \\
\hline Repeat & 565 & 18.04 & 6.58 & 1.25 & 552 & 17.73 & 3.96 & 1.02 & 545 & 20.37 & 4.49 & 1.27 & 540 & 20.58 & 3.18 & 0.91 \\
\hline Change & 662 & 24.60 & 7.57 & 1.56 & 573 & 19.48 & 6.25 & 1.79 & 567 & 21.35 & 9.21 & 1.81 & 581 & 23.04 & 6.91 & 1.50 \\
\hline
\end{tabular}


effect at the 475-msec SOA, and a determination of whether this null effect is theoretically significant is beyond the scope of the present study. However, the general pattern of results clearly indicates that the opportunity afforded in Experiment 2 for the engagement of endogenous attentional processes affected performance even when less than $200 \mathrm{msec}$ was available to do so. Indeed, the magnitude of the effect was increased by more than $50 \%$ (44 vs. $99 \mathrm{msec}$ ) when a positive predictive frequency relation was instituted. It is important to note that this modulation in the magnitude of the cuing effect cannot be attributed to an influence of response biases generated in reaction to the presentation of a predictive cue because the judgment required of listeners was orthogonal to the manipulation of frequency similarity. In addition to enhancing the frequency selectivity effect at brief SOAs, establishing a positive predictive relation between the frequencies of the cue and the target acted to eliminate the negative influence of frequency repetition at the $775-\mathrm{msec}$ SOA that was apparent in Experiment 1. It appears, then, that at lengthy SOAs when their influences over the deployment of attention are juxtaposed, the impact of an endogenous mechanism engaged in accordance with the predictive information provided by the cue may dominate over that of an exogenous process driven by the frequency of the cue.

\section{EXPERIMENT 3}

Taken together the results of Experiments 1 and 2 demonstrate that a frequency cue can exert an exogenous facilitative effect on judgments of a subsequent target within $200 \mathrm{msec}$ of its presentation and that endogenous attentional processes may augment this beneficial effect at brief SOAs and overturn it at more lengthy cuing intervals. Experiment 3 was designed as a test of these conclusions. The probability that the frequency of the target would be identical to that of the preceding cue was reduced to .25 so that on $75 \%$ of trials the cue and target differed in frequency. If an endogenous attentional mechanism can influence performance even at very brief cuing intervals, then the frequency selectivity effect apparent at 175 -msec SOA in both previous experiments should be reduced. Participants completed 32 practice and 256 experimental trials (32 trials at each of four SOAs [175, 475, $775,1,075 \mathrm{msec}$, with cue and target frequencies identical on 16 trials and different on 48 trials).

\section{Results}

Response times. Mean RTs and percent errors as a function of frequency repetition and SOA are described in Table 3. Main effects of repetition $[F(1,19)=7.789, p<$ $.02]$ and SOA $[F(3,57)=24.697, p<.001]$ were statistically significant. More important, however, there was a significant interaction between repetition and $\mathrm{SOA}[F(3,57)=$ $2.686, p=.055]$. This interaction arose because a significant negative effect of frequency repetition was apparent at SOAs of $475(p<.01)$ and $1,075(p<.01)$ msec, with no significant effect at SOAs of either $175(p=.94)$ or $775(p=.22) \mathrm{msec}$.

Errors. Statistical evaluation of the error data revealed that whereas the main effect of SOA $[F(3,57)=7.908, p<$ $.001]$ was significant, neither the main effect of frequency repetition $[F(1,19) 2.677, p=.12]$ nor the repetition $\times$ SOA interaction $[F(3,57)=1.498, p=.23]$ were. Overall, the error rate declined as SOA increased. Planned comparisons indicated that there was no difference in performance on repeat and change trials at any SOA ( $p>.09$ in all cases).

\section{Discussion}

Reducing the probability that the cue and target would be the same frequency below chance levels led to a significantly different pattern of performance than was apparent in either of the first two experiments. Specifically, reducing the probability of a frequency repetition to .25 eliminated any frequency cuing effect at an SOA of $175 \mathrm{msec}$ and generated a negative effect at SOAs of 475 and 1,075 msec. Although not statistically significant, a disadvantage of frequency repetition was apparent at the 775 -msec SOA as well. The magnitude and direction of the frequency cuing effects obtained in the three experiments, described in Figure 1, suggest that the probability of both frequency repetition and SOA influenced performance. A formal statistical comparison of performance in the three experiments confirmed this. ${ }^{3}$ Clearly, endogenous attentional processes may either complement or counteract the exogenous effect of a frequency cue at SOAs ranging from 175 to $1,075 \mathrm{msec}$.

\section{GENERAL DISCUSSION}

Taken together, the results of the three experiments reported here establish that the magnitude and the direction of the frequency selectivity effect depend both on the probability of a frequency match between cue and target

Table 3

Mean Response Times (RTs) and Percent Errors (\% E), With Standard Errors, as a Function of Frequency Repetition (Repeat or Change) and SOA $(175,475,775$, or 1,075 Msec) for Experiment 3

\begin{tabular}{|c|c|c|c|c|c|c|c|c|c|c|c|c|c|c|c|c|}
\hline \multirow{4}{*}{$\begin{array}{l}\text { Frequency } \\
\text { Repetition }\end{array}$} & \multicolumn{16}{|c|}{ Stimulus Onset Asynchrony } \\
\hline & \multicolumn{4}{|c|}{$175 \mathrm{msec}$} & \multicolumn{4}{|c|}{$475 \mathrm{msec}$} & \multicolumn{4}{|c|}{$775 \mathrm{msec}$} & \multicolumn{4}{|c|}{$1,075 \mathrm{msec}$} \\
\hline & \multicolumn{2}{|c|}{ RT } & \multicolumn{2}{|c|}{$\% \mathrm{E}$} & \multicolumn{2}{|c|}{ RT } & \multicolumn{2}{|c|}{$\% \mathrm{E}$} & \multicolumn{2}{|c|}{ RT } & \multicolumn{2}{|c|}{$\% \mathrm{E}$} & \multicolumn{2}{|c|}{ RT } & \multicolumn{2}{|c|}{$\% \mathrm{E}$} \\
\hline & $M$ & $S E$ & $M$ & $S E$ & $M$ & $S E$ & $M$ & $S E$ & $M$ & $S E$ & $M$ & $S E$ & $M$ & $S E$ & $M$ & $S E$ \\
\hline Repeat & 556 & 24.09 & 8.75 & 1.53 & 536 & 20.14 & 5.71 & 1.47 & 505 & 16.14 & 3.13 & 0.96 & 497 & 19.28 & 4.49 & 0.95 \\
\hline Change & 555 & 20.40 & 6.35 & 1.00 & 508 & 17.75 & 3.87 & 0.87 & 496 & 18.65 & 4.39 & 0.78 & 481 & 17.51 & 2.50 & 0.83 \\
\hline
\end{tabular}




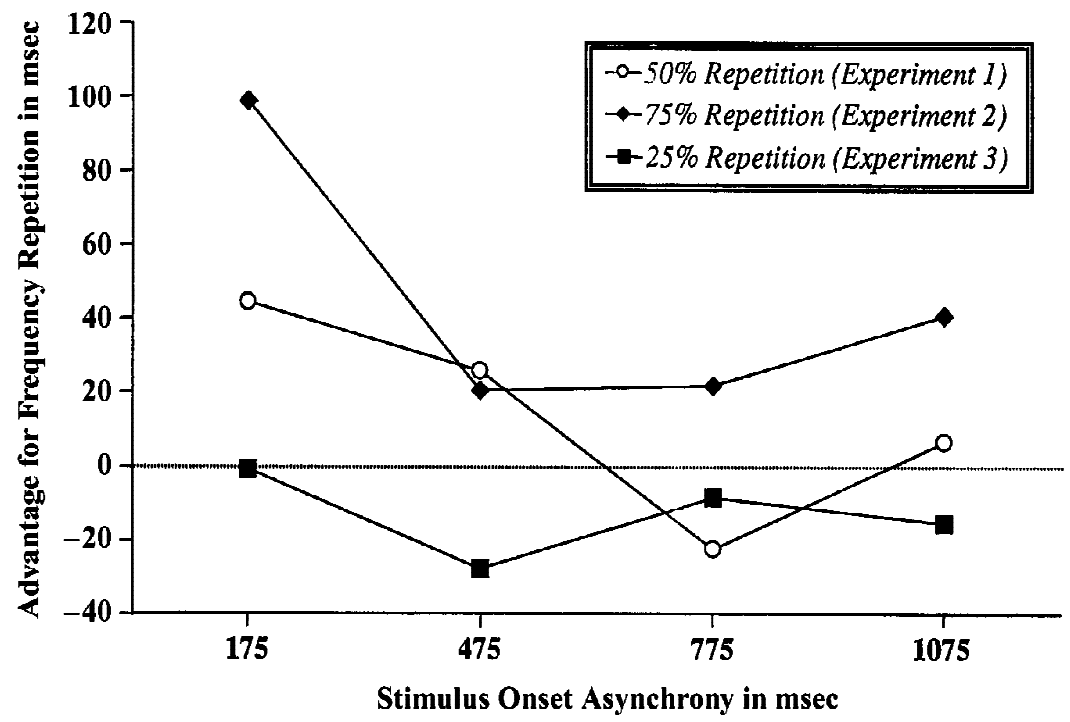

Figure 1. The magnitude of the frequency selectivity effect is described as a function of SOA and the predictability of the frequency relation between the cue and target.

and on the time period between the two sounds. In Experiment 1 , where there was no predictive relation between the frequencies of the cue and target, frequency repetition produced a beneficial effect at the 175 - and $450-\mathrm{msec}$ SOAs and a negative effect at the 775-msec SOA. In contrast, in Experiment 2, where the target was likely to be the same frequency as the preceding cue $(p=.75)$, a beneficial effect of frequency repetition was apparent at all SOAs with the magnitude of all but one of these effects significantly increased relative to the corresponding effects observed when the cue was uninformative. Finally, in Experiment 3 , instituting a negative relation between the frequencies of the cue and target so that they were more likely to be different than to be the same eliminated entirely any beneficial effect of frequency repetition and produced negative effects at the 475- and 1,075-msec SOAs.

This study was founded on the assumption, adopted either explicitly or implicitly in many previous investigations of attention, that whereas an informative cue should engage both exogenous and endogenous mechanisms, an uninformative cue should engage only the exogenous mechanism (see, e.g., Müller \& Rabbitt, 1989; Turatto et al., 2000). To the extent that this assumption is valid, the results of the present three experiments suggest that the influence of an exogenous attentional mechanism may be either reinforced and augmented or counteracted and overwhelmed by the influence of an endogenous attentional mechanism and that this interaction may occur at SOAs ranging from less than $200 \mathrm{msec}$ to more than $1 \mathrm{sec}$. Previous investigators have shown that the magnitude of the frequency selectivity effect could be modulated by payoffs, instructions to listeners, and manipulations of the relative probability of different signals (e.g., Penner, 1972; Sorkin, Pastore, \& Gilliom, 1968; Swets \& Sewall, 1961; but see also Larkin \& Greenberg, 1970, who reported no effect of instructions and payoffs). However, to our knowledge, this is the first demonstration that endogenous and exogenous attentional processes engaged in response to a frequency cue may interact, even at very brief SOAs, to enhance, extend, or reverse the frequency selectivity effect.

According to additive factors logic (e.g., Sternberg, $1969 \mathrm{a}, 1969 \mathrm{~b})$, the interaction between exogenous and endogenous attentional processes we observed may be interpreted as evidence that both avenues of attentional control influence the same cognitive processing stage. This is consistent with previous suggestions made by Mondor and colleagues (e.g., Mondor, 1999; Mondor et al., 1998). Briefly, Mondor suggested that an advance cue acts to establish an attentional template or filter based on the perceptual characteristics of the cue itself. The speed with which the subsequently presented target is transmitted to memory depends on its match with this template, with a better match leading to faster transmission. Thus, a target representation should be passed to memory more quickly on trials on which the cue and target are identical, and this faster transmission may lead directly to faster evaluation of the sound file, and to a faster response. (Evidence consistent with the existence of such a multifeature template has been reported by Wright \& Dai, 1994, who found that detection of a target was influenced by its match in both frequency and duration with a preceding cue, and by Mondor, Zatorre, \& Terrio, 1998, who found that target identification was influenced by its similarity in both frequency and location to a preceding cue.)

Critically, Mondor (1999) suggested that the time period over which an effective template description is maintained may be either abbreviated or extended through an endogenous or top-down process acting in accordance 
with the predictability of the cue-target relation. Thus, when the frequency of the target is likely to be the same as that of the cue (as in Experiment 2, above), the template will be extended and a performance advantage for trials on which the frequencies of the two sounds match will be extended across relatively lengthy SOAs. However, this account alone cannot explain the fact that a significantly larger facilitative effect was obtained when the cue and target frequencies were likely to match than when there was no predictive relation between the two. One possibility is that elevating the probability of a frequency match serves both to extend the effective duration of an attentional template and to increase its specificity. Such a refined definition of the template might then magnify the effect of frequency repetition relative to that apparent when there is no predictable frequency relation. In contrast, it appears that when the target is likely to differ from the cue (as in Experiment 3, above), the definition of the template as established by the cue itself may be overridden and reversed. This modification of the template specification appears to generate at lengthy SOAs a performance advantage for trials on which the cue and target differ, and to negate any beneficial effect of the exogenous process even at intervals as brief as $175 \mathrm{msec}$. These proposals regarding the way in which auditory cues may influence target judgments are consistent not only with the present results but also with the effects of uninformative frequency, location, timbre, intensity, and duration cues that have been reported over the last few years (Mondor \& Breau, 1999; Mondor et al., 1998; Mondor \& Lacey, 2001). However, regardless of the theoretical utility of this approach, the results reported in the three experiments described here establish that the magnitude and the direction of the frequency selectivity effect are governed both by the predictability of the frequency relation between the cue and target and by the period of forewarning provided by the cue. It is clear that exogenous and endogenous attentional mechanisms may operate in concert or in opposition to control the attentional response of the human listener to a frequency cue.

\section{REFERENCES}

Bregman, A. S., Achim, A., \& Ahad, P. A. (1992). The Maple software system. Montreal: McGill University, Department of Psychology.

BroadBent, D. E. (1952). Failures of attention in selective listening. Journal of Experimental Psychology, 44, 51-55.

BROADBENT, D. E. (1954). The role of auditory localization in attention and memory span. Journal of Experimental Psychology, 47, 191-196.

BRoAdBEnT, D. E. (1957). A mechanical model for human attention and immediate memory. Psychological Review, 64, 205-215.

Broadbent, D. E. (1958). Perception and communication. London: Pergamon.

Cherry, E. C. (1953). Some experiments on the recognition of speech, with one and with two ears. Journal of the Acoustical Society of America, 25, 975-979.

Cherry, E. C., \& TAYlor, W. K. (1954). Some further experiments upon the recognition of speech with one and with two ears. Journal of the Acoustical Society of America, 26, 554-559.

Creelman, C. D. (1959). Detection of signals of uncertain frequency. Journal of the Acoustical Society of America, 32, 805-810.

Dawson, M. E., \& Schell, A. M. (1982). Electrodermal responses to attended and nonattended significant stimuli during dichotic listening. Journal of Experimental Psychology: Human Perception \& Performance, 8, 315-324.

Egan, J. P., Carterette, E. C., \& Thwing, E. J. (1954). Some factors affecting multi-channel listening. Journal of the Acoustical Society of America, 26, 774-782.

Giard, M. H., Collet, L., Bouchet, P., \& Pernier, J. (1994). Auditory selective attention in the human cochlea. Brain Research, 633, 353-356.

Glucksberg, S., \& Cowen, G. N. (1970). Memory for nonattended auditory material. Cognitive Psychology, 1, 149-156.

GreEn, D. M. (1961). Detection of auditory sinusoids of uncertain frequency. Journal of the Acoustical Society of America, 33, 897-903. Green, D. M., McKey, M. J., \& Licklider, J. C. R. (1959). Detection of a pulsed sinusoid in noise as a function of frequency. Journal of the Acoustical Society of America, 31, 1446-1452.

Greenberg, G. Z., \& LARKIN, W. D. (1968). Frequency-response characteristic of auditory observers detecting signals of a single frequency in noise: The probe-signal method. Journal of the Acoustical Society of America, 44, 1513-1523.

Hafter, E. R, Schlauch, R. S., \& TAng, J. (1993). Attending to auditory filters that were not stimulated directly. Journal of the Acoustical Society of America, 94, 743-747.

HeNKe, W. L. (1990). An interactive dialogue language for time signal processing. Cambridge, MA: MIT Research Laboratory of Electronics.

HiRsch, I. J. (1950). The relation between localization and intelligibility. Journal of the Acoustical Society of America, 22, 196-200.

HüBner, R., \& Hafter, E. R. (1995). Cuing mechanisms in auditory signal detection. Perception \& Psychophysics, 57, 197-202.

Katzin, B. E., Corballis, M. C., \& Lockhart, R. S. (1972). Attentional strategies in dichotic listening. Canadian Journal of Psychology, 26, 207-218.

Kinchla, R. A. (1992). Attention. Annual Review of Psychology, 43, 711-742.

Koск, W. E. (1950). Binaural localization and masking. Journal of the Acoustical Society of America, 22, 801-804.

LABERge, D. (1995). Attentional processing: The brain's art of mindfulness. Cambridge, MA: Harvard University Press.

Larkin, W., \& Greenberg, G. Z (1970). Selective attention in uncertain frequency detection. Perception \& Psychophysics, 8, 179-184.

LiCKLIDER, J. C. R. (1948). The influence of interaural phase relations upon the masking of speech by white noise. Journal of the Acoustical Society of America, 20, 150-159.

Macmillan, N. A., \& Schwartz, M. (1975). A probe-signal investigation of uncertain-frequency detection. Journal of the Acoustical Society of America, 58, 1051-1058.

McCormick, P. A. (1997). Orienting attention without awareness. Journal of Experimental Psychology: Human Perception \& Performance, 23, 168-180.

Mondor, T. A. (1999). Predictability of the cue-target relation and the time-course of auditory inhibition of return. Perception \& Psychophysics, 61, 1501-1509.

Mondor, T. A., \& Breau, L. M. (1999). Facilitative and inhibitory effects of location and frequency cues: Evidence of a modulation in perceptual sensitivity. Perception \& Psychophysics, 61, 438-444.

Mondor, T. A., Breau, L. M., \& Milliken, B. (1998). Inhibitory processes in auditory selective attention: Evidence of location-based and frequency-based inhibition of return. Perception \& Psychophysics, 60, 296-302.

Mondor, T. A., \& Bregman, A. S. (1994). Allocating attention to frequency regions. Perception \& Psychophysics, 56, 268-276.

MONDOR, T. A., \& LACEY, T. E. (2001). Facilitative and inhibitory effects of cuing sound duration, intensity, and timbre. Perception \& Psychophysics, 63, 726-736.

Mondor, T. A., ZAtorre, R. J., \& Terrio, N. A. (1998). Constraints on the selection of auditory information. Journal of Experimental Psychology: Human Perception \& Performance, 24, 66-79.

Moore, B. C. J., Hafter, E. R., \& Glasberg, B. R. (1996). The probesignal method and auditory-filter shape: Results from normal and hearing-impaired subjects. Journal of the Acoustical Society of America, 99, 542-552.

Moray, N. (1959). Attention in dichotic listening: Affective cues and 
the influence of instructions. Quarterly Journal of Experimental Psychology, 12, 214-220.

Moray, N. (1972). Listening and attention. Baltimore: Penguin.

MülleR, H. J., \& RABbitT, P. M. A. (1989). Reflexive and voluntary orienting of visual attention: Time course of activation and resistance to interruption. Journal of Experimental Psychology: Human Perception \& Performance, 15, 315-330.

Niccum, N., Speaks, C., Katsuki-Nakamura, J., \& Leathers, R. (1989). Effects of decision variables on stimulus dominance in dichotic listening. Journal of Speech \& Hearing Research, 32, 184-188.

Pashler, H. E. (1998). The psychology of attention. Cambridge, MA: MIT Press.

Penner, M. J. (1972). The effect of payoffs and cue tones on detection of sinusoids of uncertain frequency. Perception \& Psychophysics, 11, 198-202.

Peters, R. W. (1954). Competing messages: The effect of interfering messages upon the reception of primary messages (U.S. Naval School of Aviation Medicine Research Report, Project No. NM 001.064.01.27). Pensacola, FL: U.S. Navy.

PoSNer, M. I. (1978). Chronometric explorations of mind. Hillsdale, NJ: Erlbaum.

Scharf, B., Quigley, S., Aoki, C., Peachey, N., \& Reeves, A. (1987). Focused auditory attention and frequency selectivity. Perception \& Psychophysics, 42, 215-223.

Schlauch, R. S., \& Hafter, E. R. (1991). Listening bandwidths and frequency uncertainty in pure-tone signal detection. Journal of the Acoustical Society of America, 90, 1332-1339.

SHAw, M. L. (1980). Identifying attentional and decision-making components in information processing. In R. W. Nickerson (Ed.), Attention and performance VIII (pp. 277-296). Hillsdale, NJ: Erlbaum.

SHAw, M. L. (1984). Division of attention among spatial locations: A fundamental difference between detection of letters and detection of luminance increments. In H. Bouma \& D. G. Bouwhuis (Eds.), Attention and performance X: Control of language processes (pp. 109-120). Hillsdale, NJ: Erlbaum.

Sorkin, R. D., Pastore, R. E. \& Gilliom, J. D. (1968). Signal probability and the listening band. Perception \& Psychophysics, 4, 10-12.

Spieth, W., Curtis, J. F., \& Webster, J. C. (1954). Responding to one of two simultaneous messages. Journal of the Acoustical Society of America, 26, 391-396.

STERnBERG, S. (1969a). The discovery of processing stages: Extensions of Donders' method. Acta Psychologica, 30, 276-315.

STERnBERG, S. (1969b). Memory-scanning: Mental processes revealed by reaction-time experiments. American Scientist, 57, 421-457.

SwETs, J. A. (1963). Central factors in auditory-frequency sensitivity. Psychological Bulletin, 60, 429-440.

SwETs, J. A., \& SEwAll, S. T. (1961). Stimulus vs. response uncertainty in recognition. Journal of the Acoustical Society of America, 33, 1586-1592.

Tolhurst, G. C., \& Peters, R. W. (1956). The effect of attenuating one channel of a dichotic circuit upon the word reception of dual messages. Journal of the Acoustical Society of America, 28, 602-605.

Treisman, A., Squire, R, \& Green, J. (1974). Semantic processing in dichotic listening? A replication. Memory \& Cognition, 2, 641-646.

Turatto, M., Benso, F., Facoetti, A., Galfano, G., Mascetti, G. G., \& Umiltà, C. (2000). Automatic and voluntary focusing of attention. Perception \& Psychophysics, 62, 935-952.

Wright, B. A., \& DAI, H. (1994). Detection of unexpected tones with short and long durations. Journal of the Acoustical Society of America, 95, 931-938.

Yama, M. F., \& Robinson, D. E. (1982). Comparison of frequency selectivity for the monaural and binaural hearing systems: Evidence from a probe-frequency procedure. Journal of the Acoustical Society of America, 71, 694-700.

\section{NOTES}

1. We will use the term exogenous to refer to a stimulus-driven or bottom-up effect and the term endogenous to refer to a top-down effect engaged in accordance with a predictive relation between cue and target, or with the information provided through verbal instructions.

2. A mixed-design ANOVA was used to compare the influence of frequency repetition and SOA on performance in Experiment 1 with that in Experiment 2. This analysis revealed significant differences in the influence of frequency repetition $[F(1,38)=19.964, p<.001]$, but not of SOA $(F<1)$ in the two experiments. Critically, however, the three-way interaction between repetition, $\mathrm{SOA}$, and experiment was also significant $[F(3,114)=4.149, p<.01]$. Further analysis indicated that the frequency repetition effect differed between experiments at all SOAs $(p<$ .01 for all comparisons) except $475 \mathrm{msec}(p=.77)$.

3. A mixed-design ANOVA was used to compare the magnitude and direction of the frequency selectivity effect apparent at each SOA for all three experiments to evaluate the extent to which predictability and SOA interact in determining performance. As might be expected given the different performance patterns in the three experiments, this examination revealed a significant three-way interaction between repetition, SOA, and experiment $[F(3,171)=5.777, p<.001]$. Further investigation of this effect indicated that the cuing effects obtained in the three experiments differed significantly from one another at the 175-, 475-, and 1,075 -msec SOAs ( $p<.01$ in all cases). At the 775 -msec SOA, whereas performance in Experiment 2 differed significantly from that in both Experiments 1 and 3 ( $p<.01$ for both comparisons), the difference in performance for the later two experiments only approached significance $(p=.13)$.
(Manuscript received November 2, 2001; revision accepted for publication May 1, 2002.) 